\title{
A Programmable Voltage Source with High Speed Current Feedback Protection
}

\author{
Jan Broulím \\ University of West Bohemia \\ and Czech Technical University in Prague \\ Czech Republic \\ broulim@kae.zcu.cz
}

\author{
Jan Moldaschl, Vjačeslav Georgiev \\ University of West Bohemia \\ Pilsen, Czech Republic \\ moldy@kae.zcu.cz, georg@kae.zcu.cz
}

\begin{abstract}
In this paper we propose a design of a programmable voltage source with high speed current feedback for disconnecting the electronics when the over current occurs. Short circuits may occur in electronics used in ionizing radiation environment because of Single Event Effects (SEEs) in semiconductors. The voltage source is designed as a supply for electronics working in ionizing radiation environment, mainly during reliability tests in particle accelerators and nuclear reactors. Circumstances of the design are described and the measurements are provided. In addition, a thermal radiating model for vacuum is presented.
\end{abstract}

Keywords- over current; programable voltage source; reliability test; single event effects

\section{INTRODUCTION}

Electronics working in ionizing radiation environment is exposed to the collisions with particles. These collisions may cause Single Event Effects (SEEs), which leads to short circuits and possible damages of the electronics. In order to protect the electronics against possible damages, we propose a design of a voltage supply with high speed current feedback. If a short circuit occurs during some reason, the fast feedback disconnects the electronics from the power voltage.

Radiation hardened expositions of electronics are necessary for reliability measurements usually performed in particle accelerators or nuclear reactors. When a particle accelerator is used for electronics testing, the electronics can be located in a vacuum chamber, where thermal conditions become a crucial issue. Only thermal radiation can be considered for cooling. For this reason, we provide a model of requirements for the heat sink used for cooling the power dissipations of the voltage source.

The output voltage is desired to operate in the range from zero voltage. Because voltage regulators available in the market usually do not allow a regulation below the internal reference voltage level, an additional circuit is needed.

The paper is organized as follows. In Sections II we describe a design of a circuit enabling the voltage regulation. In Section III we provide a circuit enabling a fast disconnection of the electronics when the overcurrent occurs. In Section IV we model a cooling in vacuum and in Section $\mathrm{V}$ we present real measurements performed on a selected linear regulator.

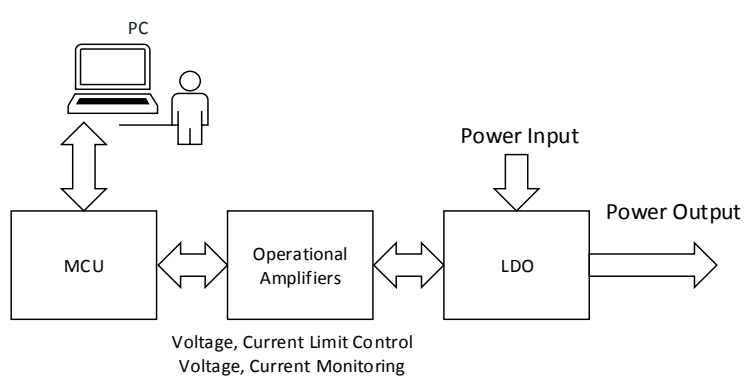

Fig. 1. Simplified block diagram

\section{VOLTAGE CONTROL}

In order to regulate the output voltage in the range starting at the zero voltage, which is below the internal reference value, we provide a design of a circuit based on operational amplifiers. The circuit is shown in Fig. 1. The proposed circuit variables can be described by the following equation:

$$
\frac{V_{\text {out }}-V_{\text {ref }}}{R_{3}}=\frac{\left(V_{\text {ref }}-V_{D A C_{-}} V_{R_{a}+R_{b}}\left(1+\frac{R_{2}}{R_{1}}\right)\right)}{R_{4}}
$$

where $V_{\text {out }}$ is the output voltage, $V_{\text {ref }}$ is the internal reference voltage in the regulator, $V_{D A C_{-} V}$ is the adjustable value outgoing from digital to analog converter and $R_{1}, R_{2}, R_{3}, R_{4}, R_{a}, R_{b}$ are the resistors in the circuit.

The output voltage can be expressed by the formulas below.

$$
\begin{gathered}
V_{\text {out }}=V_{\text {ref }}\left(1+\frac{R 3}{R 4}\right)-V_{D A C_{-} V} R \\
R=\frac{R_{b}}{R_{a}+R_{b}} \frac{R_{3}}{R_{4}}\left(1+\frac{R_{2}}{R_{1}}\right)
\end{gathered}
$$

As can be seen, the resistors $R_{3}$ and $R_{4}$ determine the maximum output voltage.

After considering $R_{1}=R_{2}$, the minimum value of the ratio $R_{b} /\left(R_{a}-R_{b}\right)$ should be chosen according to the following formula:

$$
\min \left(\frac{R_{b}}{R_{a}-R_{b}}\right)=\frac{\max \left(V_{\text {out }}\right)}{\max \left(V_{D A C_{-} V}\right)} \frac{R_{4}}{2 R_{3}}
$$




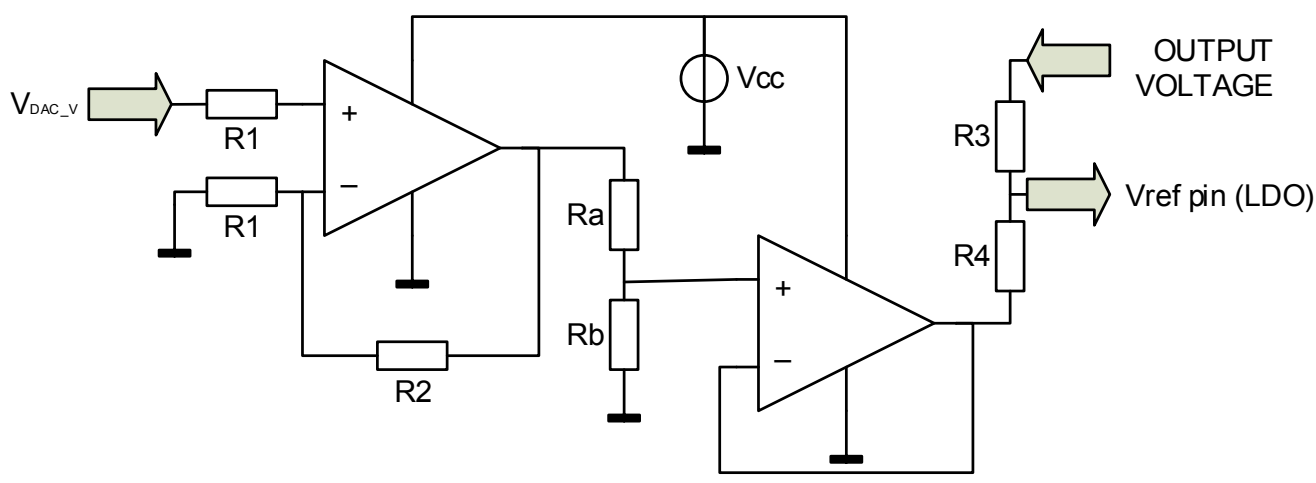

Fig. 2. Circuit for voltage regulation at the range of 0 to $V \max$

This enables the regulation of the output voltage in the range from zero voltage.

\section{CURRENT Limitation}

The voltage supply is designed as double protected in order to provide more safety when a short circuit occurs. The main protection is provided through the circuit including operational amplifiers, a comparator and a D flip-flop. The circuit processes a voltage drop on the sense resistor Rs and a voltage outgoing from digital-to-analog $\left(V_{D A C_{-} I}\right)$ converter. The voltage drop is precisely amplified and compared with the value $V_{D A C_{I}}$. The precision of the amplification is crucial because low voltage drops are on the resistor Rs (the resistance can be below $3 \mathrm{mOhms}$ in real applications). If the amplified voltage exceeds the $V_{D A C_{-} I}$ level, the comparator is switched. The output of the D flip-flop, connected to the enable pin of the LDO regulator, is set to zero and the regulator is switched off. After resetting the enable signal, the output is switched off. The delay between the instant when the output current exceeds a programmed level $V_{D A C_{-} I}$ and resetting the enable pin is limited only by the slew rate of the operational amplifiers and propagation delays of the comparator and the D flip-flop. The fast disconnection, in the order of microseconds, of supplied electronics avoids possible damages of the electronics caused by SEE. The circuit allowing the protection described in this paragraph is shown in Fig. 3.

The amplified value incoming to the comparator denoted as $V_{\text {COMP }}$ is the following:

$$
V_{\text {COMP }}=I_{L O A D} * R_{S}\left(1+\frac{2 R_{2}}{R_{1}}\right) \frac{R_{4}}{R_{3}}
$$

where $I_{L O A D}$ is the load current, Rx are the resistors in the circuit and $\mathrm{C} 1$ is the capacitor desired for preventing oscillations (value of $100 \mathrm{pF}$ is convenient).

The maximum output current is derived as:

$$
I_{M A X}=\frac{V_{D A C I} I}{R_{S}\left(1+\frac{2 R_{2}}{R_{1}}\right) \frac{R_{4}}{R_{3}}}
$$

An additional protection is provided in the case when the main protection fails. If the main protection fails due to some reason, the output current is still limited by the internal circuit of the LDO regulator. The value of the maximum current depends on the resistance of the resistor Rs. Although the supplied electronics is not disconnected in this case, the load

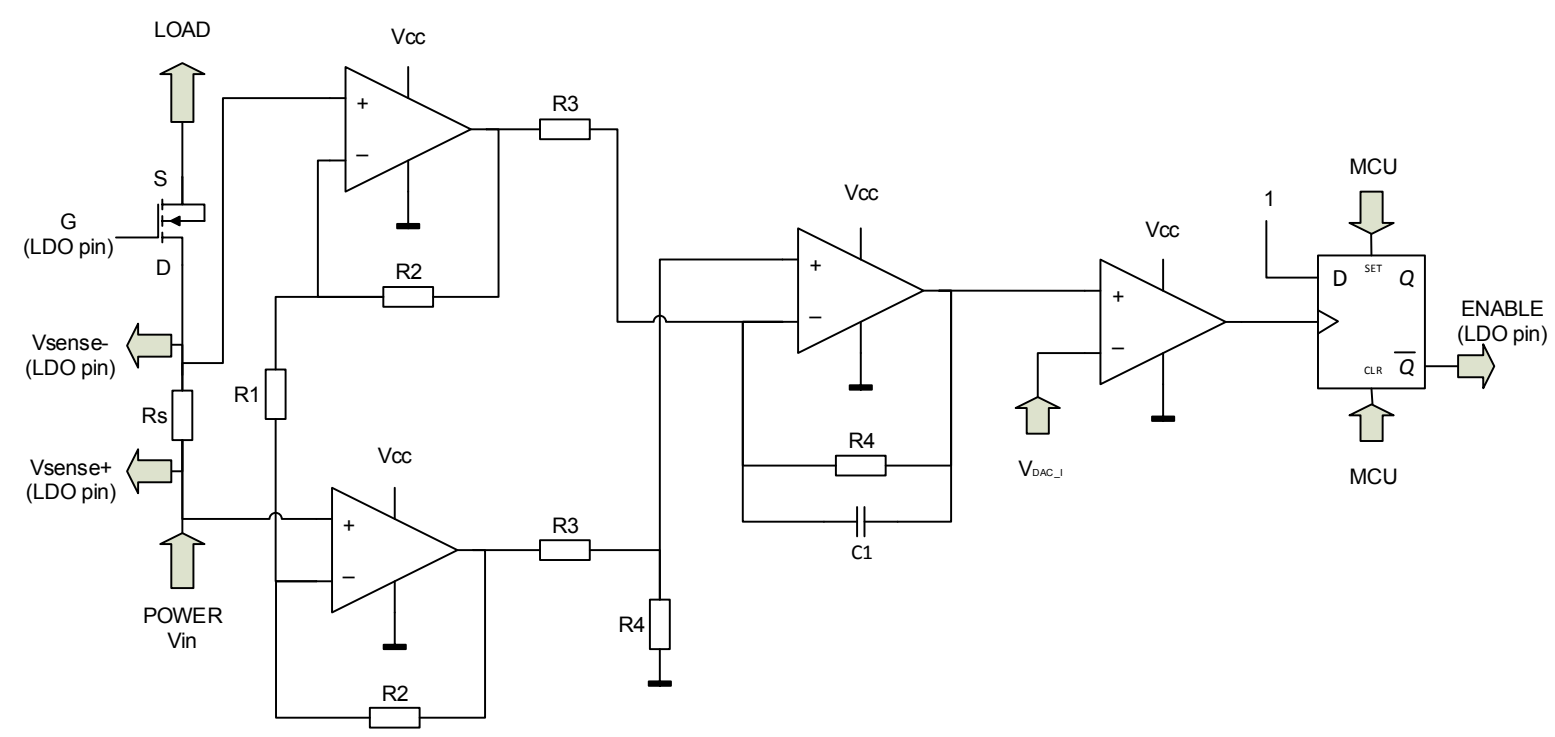

Fig. 3. Current limitation providing a double protection 
current is limited and the voltage source is protected from damage.

\section{COOLING}

\section{A. Preliminary theory}

The linear voltage supply is in general the source of waste heat caused by the voltage drop on the power transistor. Because the presented voltage source is designated for applications in vacuum, where only thermal radiation can be considered, cooling is necessary to be modelled.

Generally known Stefan-Boltzmann law describing the power radiated from a black body is given by the following formula:

$$
j=\sigma T^{4},
$$

where $j$ is the emitted energy per square meter $\left(\mathrm{Wm}^{-2}\right), T$ is the thermodynamic temperature and $\sigma$ is the Stefan-Boltzmann constant derived from the Boltzmann constant and Planck's constant.

Supposing the power dissipation on the transistor to be denoted as $P$, the heat change $Q$ can be derived as follows:

$$
\frac{d Q}{d t}=m c \frac{d T}{d t}=P-\sigma T^{4} S,
$$

where $m$ is the mass of the heat sink, $S$ is the surface

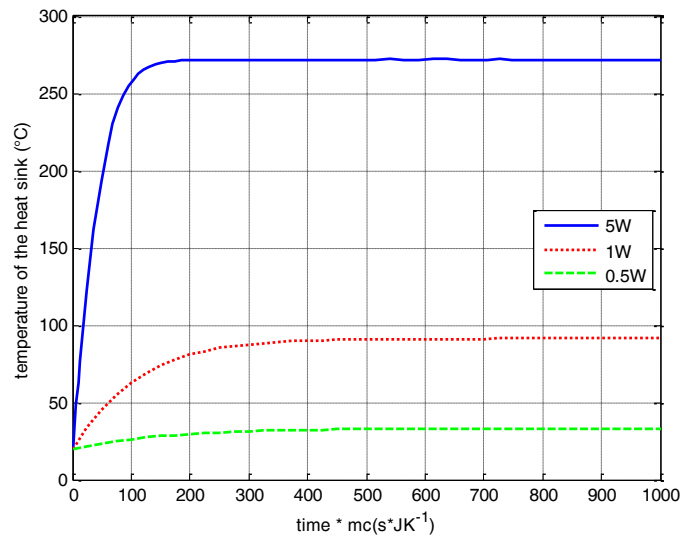

Fig. 4. Convergence of the temperature of the heat sink for constant power dissipations.

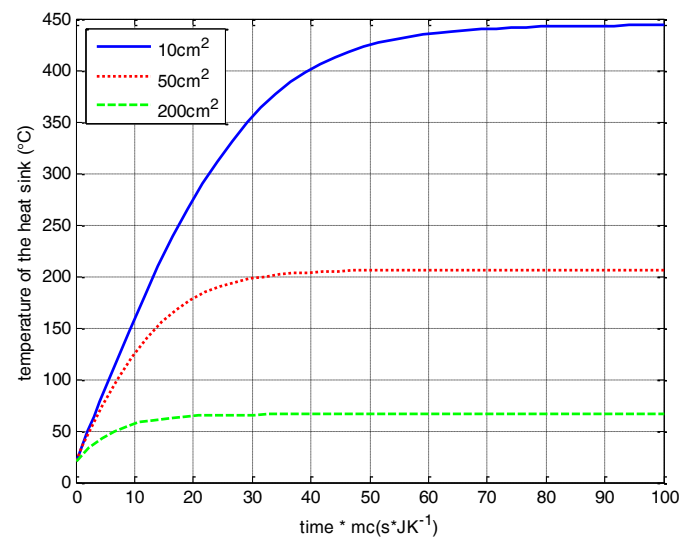

Fig. 5. Convergence of the temperature of the heat sink for constant power dissipations. of the heat sink and $\mathrm{c}$ is the specific heat capacity of the material (for aluminum $896 \mathrm{Jkg}^{-1} \mathrm{~K}^{-1}$ ).

The temperature difference can be expressed by the formula below [2]:

$$
\frac{d T}{d t}=\frac{P-\sigma T^{4} S}{m c},
$$

\section{B. Simulated results}

The differential equations are simulated by the Runge-Kutta method for different power dissipations. The results can be seen in Fig. 4.

The second simulation (Fig. 5) models temperature convergence for the power dissipation of $15 \mathrm{~W}$. Three values of the heat sink surface are considered; $10 \mathrm{~cm}^{2}, 50 \mathrm{~cm}^{2}$ and $200 \mathrm{~cm}^{2}$.

Tables I, II and III provide the values of stabilizes temperatures for different surfaces of the heat sink.

\section{REAL MEASUREMENTS}

The LDO regulator MIC5158 [3] was selected for the application, because of excellent parameters of this regulator. The measurement was performed on the circuit built of fast operational amplifiers OPA727 [4] and the FET transistor IRL3103 [5]. The selected components enables operation up to the load of $10 \mathrm{~A}$.

In addition, the voltage stability was measured. No changes in terms of millivolts were observed when a load was not connected. A difference of 15 millivolts was observed when the output current was set to $1 \mathrm{~A}$ (Table IV). The change was probably caused by the increasing temperature. It can be compensated by more robust heat sink or by an additional feedback from the output to the microcontroller.

TABLE I

STABILIZED TEMPERATURES FOR THE POWER DISSIPATION OF 5W

\begin{tabular}{c|c|c|c}
\hline \hline$S\left(\mathrm{~cm}^{2}\right)$ & 10 & 50 & 100 \\
\hline Stabilized temperature $\left({ }^{\circ} \mathrm{C}\right)$ & 271.8 & 91.27 & 33.29 \\
\hline \hline
\end{tabular}

TABLE II

STABILIZED TEMPERATURES FOR THE POWER DISSIPATION OF $15 \mathrm{~W}$

\begin{tabular}{c|c|c|c}
\hline \hline$S\left(\mathrm{~cm}^{2}\right)$ & 100 & 200 & 300 \\
\hline Stabilized temperature $\left({ }^{\circ} \mathrm{C}\right)$ & 130.1 & 65.98 & 33.29 \\
\hline \hline
\end{tabular}

TABLE III

STABILIZED TEMPERATURES FOR THE POWER DISSIPATION OF $30 \mathrm{~W}$

\begin{tabular}{c|c|c|c}
\hline \hline$S\left(\mathrm{~cm}^{2}\right)$ & 200 & 300 & 400 \\
\hline Stabilized temperature $\left({ }^{\circ} \mathrm{C}\right)$ & 130.1 & 91.26 & 65.98 \\
\hline \hline
\end{tabular}




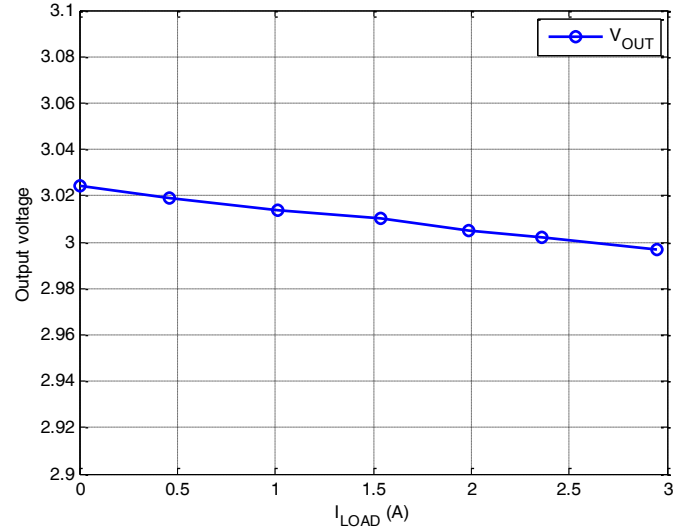

Fig. 5. Load characteristic measured up to the output current of $3 \mathrm{~A}$

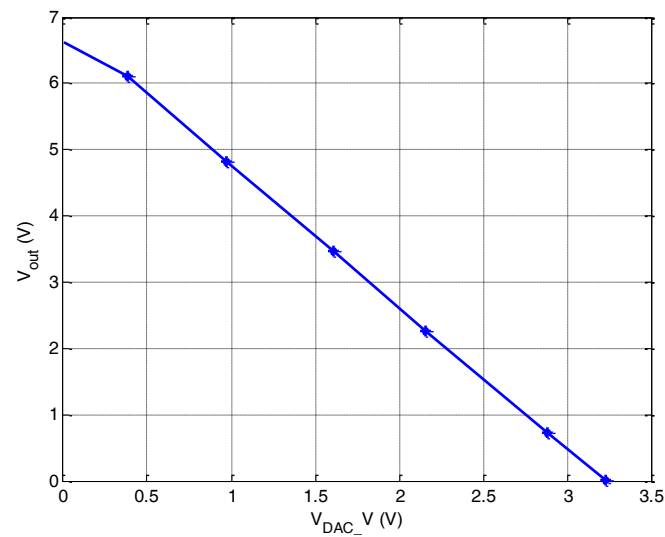

Fig. 6. Measured power output voltage to the voltage of a digital to analog converter.

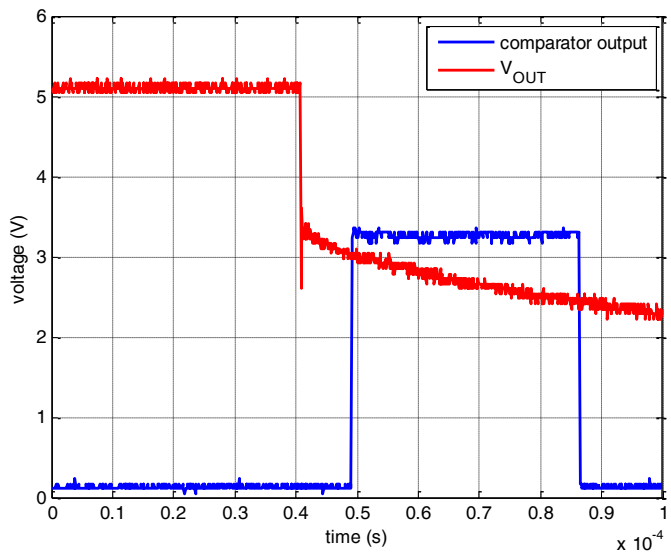

Fig. 7. Measured response on a short-cicuit at the output.

TABLE IV

MEASURED TIME STABILITY WHEN OUTPUT CURRENT IS SET TO $1 \mathrm{~A}$

\begin{tabular}{c|c|c|c|c}
\hline \hline Time & $t$ & $t+5 \min$ & $t+15 \min$ & $t+60 \min$ \\
\hline $\begin{array}{c}\text { Output } \\
\text { voltage }\end{array}$ & 0.932 & 0.933 & 0.941 & 0.948 \\
\hline \hline
\end{tabular}

\section{CONCLUSIONS}

In this paper we proposed a design of a programmable voltage source with high speed current feedback. The voltage source was designed as a supply for electronics working in ionizing radiation environment, mainly during reliability tests in particle accelerators and nuclear reactors. The measurements confirmed proper functionality of a sample build according to the calculations provided in the paper. The sample was debugged and tested.

For the future work, a bipolar voltage source to be designed. An additional feedback to the microcontroller from the output for compensating power voltage differences is considered. Such differences are caused mainly by the load and temperature changes.

\section{ACKNOWLEDGMENT}

This work was supported by the project of Centre for Advanced Nuclear Technologies, no. TE01020455; provided by the Technology Agency of the Czech Republic.

\section{REFERENCES}

[1] P. Broulim, J. Bartovsky, J. Broulim, P. Burian, V. Georgiev, M. Holik, V. Kraus, A. Krutina, J. Moldaschl, V. Pavlicek, S. Pospisil, J. Vlasek, "Compact device for detecting single event effects in semiconductor components," Telecommunications Forum Telfor (TELFOR), 23rd, Belgrade, pp. 639-642. doi: 10.1109/TELFOR.2015.7377548. 2015

[2] John R. Howell, M. Pinar Menguc, Robert Siegel, "Thermal Radiation Heat Transfer". CRC Press, 2011.

[3] Super LDO Regulator Controller MIC5156/5157/5158. Datasheet. Micrell, Inc. 1999.

[4] OPA727, High Precision CMOS Operational Amplifier. Datasheet. Texas Instruments, 2007.

[5] IRL3103 Power MOSFET. Datasheet. International Rectifier, 2001 .

[6] Technical Review of Low Dropout Voltage Regulator Operation and Performance, Application Report, Texas Instruments, 1999. 